\title{
¿DERECHOS HUMANOS PARA QUIÉNES? REFLEXIONES SOBRE ALGUNAS CUESTIONES EMBARAZOSAS
}

\author{
Luis Villavicencio Miranda*
}

RESUMEN

Este artículo examina algunos de los problemas a los que nos enfrentamos cuando intentamos conceptualizar apropiadamente el término derechos humanos. En primer lugar, expone las paradojas que se siguen de las dos formas tradicionales de definir el conjunto de los titulares de tales derechos: la personalidad moral y la pertenencia a la especie humana. Luego, examina el problema de la titularidad de los derechos en el caso de los niños. Y, para terminar, analiza la clase de derechos subjetivos que son los derechos bumanos.

PERSONALIDAD MORAL - ESPECISMO - DERECHOS MORALES

Human rights to whom? Thinking about embarrassing issues

\section{ABSTRACT}

This article examines some of the problems that are exposed when we try to figure out the appropriate conceptualization of human rights. Foremost, it explores the paradoxes ensuing the two traditional forms of definition in the titlebolders of such rights: the moral personality and the ownership of buman race. Subsequently, it revises the problem of children's ownership rights. Finally, it reviews which type of subjective rights are the human rights.

MORAL PERSONALITY - SPECISM - MORAL RIGHTS

* Abogado, Doctor en Derecho, Profesor de la Escuela de Derecho de la Universidad de Valparaíso, Errázuriz 2120, Valparaíso, Chile, luis.villavicencio@uv.cl. Artículo recibido el 9 de junio de 2008 y aceptado para su publicación por el Comité Editorial el 24 de octubre de 2008. 


\section{INTRODUCCIÓN}

$\mathrm{S}$ i buscamos aproximarnos de manera rigurosa al estudio teórico de los derechos humanos, debemos ocuparnos al menos de dos problemas que están estrechamente vinculados: por una parte, la cuestión de su elucidación conceptual, esto es, establecer qué significado cabe atribuir al término "derechos humanos"; y, por otra, el problema de su fundamentación, es decir, construir un conjunto de argumentos, suficientemente persuasivos e intersubjetivos, que nos permitan justificar el valor de estos derechos. ${ }^{1}$

Pareciera ser, a primera vista, que la tarea de conceptualizar y fundamentar alguna expresión son cuestiones diferenciadas e independientes. Si, por ejemplo, nos preguntamos qué significado cabe atribuir a la expresión "justicia” podemos llegar a convenir alguno y, más tarde, intentar determinar si la "justicia” es un valor que merece ser respetado o promovido. La pertinencia de la distinción parece ser indiscutible, la tarea de elucidación conceptual es previa e independiente de la de la valoración de los fenómenos referidos por los conceptos en cuestión, ya que sin tal elucidación no es posible saber qué es lo que se está valorando.

Esta distinción, que parece tan clara, deja de serlo cuando vemos el asunto desde el punto de vista inverso. Parece igualmente válido postular que difícilmente pueda uno llegar a dar el concepto de algo sin tener alguna noción, por mínima que sea, de la fundamentación de ese algo. ¿Cómo salimos de este aparente atolladero? La forma de conciliar esta paradoja es comprender que existe un proceso de ajuste entre la elucidación conceptual y la tarea de fundamentar. Se trata de dar o convenir algún concepto provisorio de la expresión que pueda estar sujeto a revisión cuando dicha expresión sea sometida a un test de valoración.

Esclarecido el punto anterior, ¿de qué manera establecemos un concepto de derechos humanos? Descartada la posibilidad de que una definición consista en dar cuenta de alguna esencia inobservable, ${ }^{2}$ reflejada por el concepto en cuestión, las posibilidades que quedan disponibles son una investigación lexicográfica acerca del uso de una cierta expresión lingüística, tal como la que se lleva a cabo en la confección de un diccionario, o la proposición de una definición estipulativa que simplemente signifique la decisión del hablante de usar la expresión en un determinado sentido. Sin embargo, como se sabe, ambas posibilidades son insatisfactorias. Miradas así las cosas aparece como productiva una vía intermedia constituida por la reconstrucción racional de la expresión a la luz de su uso por una comunidad de hablantes determinada, transformando un concepto inexacto y vago en otro que sea menos inexacto y menos vago y que, por lo tanto, sea útil al momento de fundamentarlo. ${ }^{3}$

${ }^{1}$ Peña, C., "Sobre el concepto y el fundamento de los derechos humanos", en Cuadernos de Análisis Jurídico, Escuela de Derecho de la Universidad Diego Portales, N²7, 1993, pp. 7-20.

${ }^{2}$ Estoy pensando en alguna teoría esencialista del lenguaje, como la que Platón plantea en el Cratilo.

${ }^{3}$ Nino, C. S., Ética y derechos humanos, Astrea, Buenos Aires, 1989, pp. 11-14. 
Pues bien, en las líneas que siguen me concentraré en algunos de los problemas a los que nos enfrentamos cuando intentamos conceptualizar el término derechos humanos. En primer lugar, revisaré algunas de las objeciones y paradojas a las formas más típicas y tradicionales de definir el concepto que nos ocupa. En segundo lugar, expondré con detención una de esas paradojas, aquella que se relaciona con la titularidad de los derechos en el caso de los niños, niñas y adolescentes. Y, finalmente, me referiré a la cuestión de qué clase de derechos subjetivos son los derechos humanos. Cerraré este trabajo, por último, con algunas conclusiones.

\section{II. ¿QUIÉNES SON TITULARES DE DERECHOS HUMANOS?}

Partamos por un análisis muy básico tratando de contextualizar las dos unidades semánticas que componen la expresión “derechos humanos”. La palabra "derecho" está utilizada en este caso, obviamente, como la facultad o potestad que le asiste a una persona. Y la palabra "humanos" alude a que la única propiedad que ha de satisfacerse para ser titular de estos derechos es la de pertenecer a la clase de los seres humanos. Así, uno de los rasgos más decisivos de los derechos humanos está en su propio nombre, esto es, que el único requisito para ser titular de ellos es ser hombre o mujer, por lo tanto, su posesión no puede estar restringida, bajo ningún respecto, a una subclase determinada de individuos. Dicho de otra manera, los derechos humanos son una clase de derechos que se conceden considerando la pertenencia a la especie humana como única propiedad relevante de sus beneficiarios, derivándose de esta idea que los hombres y mujeres poseen un título igual para gozar de tales derechos en la medida en que todos exhiben, en el mismo grado, esa propiedad relevante. ${ }^{4}$

Ahora bien, ¿cómo sabemos cuando $\mathrm{X}$ es un hombre o mujer? Debemos darle contenido al conjunto "X". Aquí se llega, irremediablemente, a un problema desagradable: determinar qué hace que un ser humano sea humano. Frente a este dilema parece haber dos alternativas. Una, caracterizar al hombre y la mujer desde la perspectiva de su racionalidad o de la capacidad de proponerse planes de vida, pero esto nos lleva a la conclusión chocante que hay personas que valen más que otras; o también podemos considerar como ser humano al que satisface ciertas características biológicas.

Concentrémonos en la primera alternativa. Si se lee cualquier definición de derecho humano, se puede inferir sin duda que descansa en una cierta idea de la personalidad moral $^{5}$ que se distribuye por igual entre todos los seres humanos, esto es, que las personas

\footnotetext{
${ }^{4}$ Peña, C., ob. cit.

${ }^{5}$ Rawls es un buen ejemplo contemporáneo de una teoría de la justicia y de los derechos que se funda en atribuir a los seres humanos normativamente dos facultades morales básicas: tener un sentido de la justicia y adoptar una cierta concepción del bien. Así, a modo de ilustración, el filósofo estadounidense comienza su artículo "El constructivismo kantiano en la teoría moral" señalando que la justicia como equidad, presentada en $A$ Theory of Justice, es una variante kantiana del constructivismo cuyo rasgo más peculiar es "que especifica una determinada concepción de la persona como elemento de un procedimiento de construcción razonable
} 
poseemos un cierto sentido de la justicia que gobierna nuestras decisiones éticas y políticas fundada en la reciprocidad moral de reconocer al otro como un igual. "Rawls mantiene que la personalidad moral es la base de la igualdad humana, criterio que se fundamenta en su idea 'contractualista' de la justicia. La tradición contractual percibe la ética como un tipo de acuerdo mutuamente beneficioso, o expresado en palabras más llanas, 'si no me fastidias, yo no te fastidiaré'. Por tanto, sólo aquellos capaces de apreciar que no se les está fastidiando y de frenarse a su vez para no fastidiar, están dentro de la esfera de la ética". 6

Pero aquí mismo comienzan todos los problemas de utilizar la personalidad moral como base para la atribución de derechos humanos. ${ }^{7}$ En primer lugar, la personalidad moral es una cuestión de grado. Algunas personas pueden ser muy sensibles a temas de justicia y ética en general, en cambio, otras tienen una perspectiva más bien estrecha. La propuesta de que ser una persona moral es el mínimo indispensable para ser titular de derechos humanos no aclara dónde debe trazarse este mínimo; al igual que es fuertemente contraintuitiva: ¿por qué razón, si la personalidad moral es tan importante para atribuir estatus moral, no se distribuye con la misma intensidad entre todos los seres humanos?

Sin embargo, hay un inconveniente aún más serio. No sólo hay personas que poseen una personalidad moral más refinada que otros, sino que existen seres humanos que no son personas morales en ningún sentido gradual del término. Los niños pequeños, junto con sujetos que presentan discapacidades intelectuales severas, carecen, totalmente, del necesario sentido de la justicia. En consecuencia, poseer una personalidad moral no constituye una base satisfactoria para el principio de que todos los seres humanos deben ser titulares de derechos humanos.

Tratándose de los niños y niñas, es evidente -al menos hasta la adolescencia- que no poseen una personalidad moral en el sentido explicado y, por lo mismo, carecerían de la propiedad relevante para ser titulares de derechos y también para desarrollar autónomamente planes de vida. Esta objeción suele salvarse, con liviandad en mi opinión, sosteniendo que la autonomía o la personalidad moral son características que los niños y niñas poseen en potencia y, por ende, deben ser considerados dentro de la comunidad moral acreedora de derechos humanos. Pero el argumento de la potencialidad es altamente problemático.

cuyo resultado determina el contenido de los primeros principios de justicia. Dicho de otro modo: este tipo de visión establece un cierto procedimiento de construcción que responde a ciertas exigencias razonables, y dentro de ese procedimiento personas caracterizadas como agentes de construcción racionales especifican, mediante sus acuerdos, los primeros principios de la justicia". Rawls, J. "El constructivismo kantiano en la teoría moral", en Justicia como equidad. Materiales para una teoría de la justicia, Tecnos, Madrid, 1999, p. 210 (traducción de Miguel Ángel Rodilla). Bonet).

${ }^{6}$ Singer, P., Ética práctica, Cambridge University Press, 1995, p. 22 (traducción de Rafael Herrera

${ }^{7}$ Sigo a Singer en la exposición de las dificultades asociadas a la idea de personalidad moral. Ibíd., pp. 22-31. 
Para empezar, si se defiende la idea de que los niños son potencialmente personas autónomas, debemos aceptar necesariamente que todo óvulo fecundado también es una persona potencial, lo cual nos impondría la obligación moral de respetar su vida, con lo que toda clase de aborto debería estar prohibido. ${ }^{8}$ Una persona potencial es algo que ha iniciado un proceso biológico de desarrollo que culminará con la producción de una persona real, única en su especie. Ahora, el óvulo fecundado o la persona potencial, considerado como lo que es y no como lo que pudiera llegar a ser, carece de propiedades reales que nos obliguen a tratarlo como persona y que por sí mismas nos planteen exigencias morales. Hay muchos ejemplos que demuestran lo que estoy afirmando: arrancar una bellota en brote no es lo mismo que talar un roble majestuoso; meter una gallina viva en una olla de agua hirviendo es mucho peor que hacer lo mismo con un huevo; el príncipe Felipe es el rey potencial de España, pero ahora no puede exigir los derechos de un rey; un feto tiene potencialmente el derecho a sufragio, pero por supuesto su madre no podría votar doble arguyendo que una de sus opciones es la de su hijo; en fin, yo mismo soy potencialmente un profesor titular, pero no puedo ahora exigir un trato como si fuera tal, por mucho que, probablemente, llegue a serlo.

Aun cuando el óvulo fecundado o un embrión pueda ser conceptualizado como una persona potencial, al parecer ello no bastaría para justificar la creencia moral de que siempre sea reprochable interrumpir su proceso vital pues, como dijimos, carece en sí mismo de propiedades moralmente significativas y, además, la atribución de derechos en base a una propiedad que se tiene en potencia es lógicamente insostenible. Decir que "A es un X potencial" implica, precisamente al contrario de quienes defienden el argumento de la potencialidad, que "mientras A no sea $\mathrm{X}$, no tiene los derechos propios de $\mathrm{X}$ " o, todavía más claramente, puede traducirse al enunciado equivalente "A no es X".

Veamos ahora la segunda opción, esto es, considerar que satisfaciéndose determinadas propiedades biológicas se merecen ciertas posiciones normativas. ${ }^{9}$ Por ejemplo, podría considerarse que sólo por el hecho de estar vivo y de tener el ADN propio de un homo sapiens, un óvulo fecundado sería en este sentido una persona. Sin embargo, de inmediato surge una dificultad insalvable, todas nuestras células vivas tienen el ADN humano, pero no aceptaríamos, obviamente, que cada una de ellas sea una persona. Por lo tanto, es necesario agregar a esta tesis otro elemento, esto es, que además de ser un organismo vivo con el ADN humano es necesario que se haya iniciado un proceso de reproducción biológica específico, de modo que no cualquier célula sería una persona, pero un óvulo fecundado sí lo sería.

Empero, aun agregando esta restricción, intuitivamente nos parece que las obligaciones morales que se tienen frente a una persona ya nacida no son las mismas que las que se tienen frente a un óvulo fecundado. A modo de ilustración, a este último no lo podemos lastimar ya que carece de toda sensibilidad; tampoco parece como un ente

${ }^{8}$ Sobre esta cuestión puede verse Singer, P. ob. cit., pp. 167-215.

${ }^{9}$ Sigo, en lo concerniente a este punto, a Valdés, M., "El problema del aborto: tres enfoques", en Bioética y derecho. Fundamentos y problemas actuales, Rodolfo Vázquez (comp.), ITAM-Fondo de Cultura Económica, México D. F., 1999, pp. 129-150. 
cuyos deseos, intereses o planes de vida podamos contrariar, porque sencillamente no los posee; no parece ser algo con lo que podamos relacionarnos afectivamente de la misma forma en que lo hacemos con una persona ya nacida. De modo que los óvulos fecundados resultan ser distintos a las personas precisamente en aquellos aspectos que importan a la moral o a una teoría de los derechos, o sea, dolor, deseos o intereses, capacidad de concebir planes de vida y relaciones personales, etc.

Luego, las personas nos plantean ciertas exigencias morales, pero al parecer las características personales que originan esas exigencias sobrepasan la característica meramente biológica. En suma, si se dice que el cigoto es una persona por el hecho de tener un código genético humano y haber iniciado un proceso reproductivo, y que, por ende, nos impone la obligación moral de respetar su vida, o bien se está dando un salto argumentativo o bien se está pensando, no en las propiedades biológicas del cigoto, sino en sus propiedades potenciales, es decir, en lo que el cigoto podría llegar a ser. Y, como ya vimos, el argumento de la potencialidad no es convincente.

Junto con la anterior, esta segunda alternativa que sustenta una noción normativa de derechos en propiedades fácticas es falaz puesto que incurre en la llamada falacia naturalista. Para comprender esta objeción es conveniente partir por recordar la formulación canónica original de tal falacia, el conocido axioma o ley de Hume, que el filósofo escocés planteó en este célebre pasaje:

“(...) No puedo dejar de añadir a estos razonamientos una observación que puede resultar de alguna importancia. En todo sistema moral de que haya tenido noticia, hasta ahora, he podido siempre observar que el autor sigue durante cierto tiempo el modo de hablar ordinario, estableciendo la existencia de Dios o realizando observaciones sobre los quehaceres humanos, y, de pronto, me encuentro con la sorpresa de que, en vez de las cópulas habituales de las proposiciones: es y no es, no veo ninguna proposición que no esté conectada con un debe o un no debe. Este cambio es imperceptible, pero resulta, sin embargo, de la mayor importancia. En efecto, en cuanto que este debe o no debe expresa alguna nueva relación o afirmación, es necesario que ésta sea observada y explicada y que al mismo tiempo se dé razón de algo que parece absolutamente inconcebible, a saber: cómo es posible que esta nueva relación se deduzca de otras totalmente diferentes. Pero como los autores no usan por lo común de esta precaución, me atreveré a recomendarla a los lectores: estoy seguro de que una pequeña reflexión sobre esto subvertiría todos los sistemas corrientes de moralidad, haciéndonos ver que la distinción entre vicio y virtud ni está basada meramente en relaciones de objetos, ni es percibida por la razón”. ${ }^{10}$

${ }^{10}$ Hume, D., Antología, Edición de Vicente Sanfélix, Península, Barcelona, 1986, p. 177. 
Abstrayéndonos de lo que realmente quiso decir Hume en este fragmento, cuestión que es bien discutida, ${ }^{11}$ la interpretación tradicional sostiene algo difícil de refutar: de la sola observación de un hecho no se puede deducir un deber o un valor, o sea, que de un conjunto de proposiciones exclusivamente descriptivas no es posible concluir ninguna proposición de carácter prescriptivo. "Y, en efecto, que no pueden derivarse sin más normas y valores a partir de hechos es tan obvio que parece mentira que tardara tanto tiempo en formularse explícitamente, pues que el ser humano tenga de hecho tendencias violentas no prueba en absoluto que deba tenerlas, porque un hecho es sólo un hecho y si es bueno o malo no depende de su existencia”. ${ }^{12}$ Luego, la atribución de una consecuencia normativa como la titularidad de los derechos humanos no puede depender, exclusivamente al menos, de la pura pertenencia a una determinada especie o del cumplimento de ciertos atributos biológicos.

Ahora bien, la solución a los problemas que he venido apuntando es, apoyándome en Nino, ${ }^{13}$ disolverlos, puesto que lo importante es determinar cuáles son los principios morales - por ejemplo, la máxima de que es bueno evitar el sufrimiento o no provocarlode los que los derechos humanos básicos derivan y luego definir a las personas o sujetos morales como la clase de todos aquellos individuos que poseen las propiedades que son necesarias para gozar o ejercer tales derechos. En otras palabras, los principios morales de los que los derechos humanos derivan son categóricos, en el sentido de que ellos no condicionan la titularidad de tales derechos a la posesión de una u otra característica, estos principios son erga omnes, o sea, se aplican a todos y a todo.

Así entendidas las cosas, los derechos humanos son aquellos derechos que gozan todos los seres que satisfacen las propiedades normativas que consideramos relevantes para atribuir derechos. ${ }^{14}$ Si esto es así, el llamar derechos humanos a estos derechos hace referencia al hecho circunstancial de que esa clase está principalmente constituida por seres humanos. Pero nada garantiza de antemano que todas las personas morales sean hombres o mujeres y de que todos los seres humanos tengan el mismo grado de personalidad moral. Estas conclusiones no parecen ahora chocantes -como lo eran cuando las presenté vinculadas a la titularidad de los derechos- "ya que no están basadas en una limitación arbitraria del alcance de nuestros principios morales, sino en hechos claros que determinan la posibilidad o imposibilidad de ejercitar los derechos que derivan de aquéllos. Al contrario, reconocer que hay límites fácticos y no normativos a la condición

${ }^{11}$ Rawls, por ejemplo, considera que lo que el filósofo escocés realmente dijo es que la moralidad no es una cuestión de hecho que sea descubierta por el entendimiento, sino que es objeto del sentimiento y, por ende, cuando sostuvo que el "debe" no se sigue del "es" sólo estaba afirmando que no hay una ley demostrativa o normativa que conecte el sentimiento del "debe" o "no debe" con la cuestión de hecho. Sólo en este sentido el "debe" no se sigue del "es". Rawls, J., Lecciones sobre la historia de la filosofía moral, Barbara H. (comp.), Paidós, Barcelona, 2001, pp. 100 y 101 (traducción de Andrés de Francisco).

12 Ruiz Miguel, A., Una filosofía del derecho en modelos históricos, Trotta, Madrid, 2002, pp. 194 y 195.

13 Ver Nino, C. S., "Los titulares de los derechos humanos: el concepto de persona moral", en Filosofía del lenguaje, de la ciencia, de los derechos bumanos y problemas de su enseñanza, Sociedad Filosófica Iberoamericana, Universidad Nacional Autónoma de México,1987, pp. 127-146.

${ }^{14}$ Cfr. Nino, C. S., Ética y derechos humanos, ob. cit., p. 47. 
de persona moral tiene la consecuencia de admitir que los principios de los que derivan los derechos humanos prescriben una permanente extensión de esa condición, mediante la superación de los obstáculos de hecho para gozar de los derechos en cuestión”. ${ }^{15}$

Y, a propósito de extensión, la dificultad de adoptar la salida que nos propone Nino es que debemos aceptar, a menos que no nos interese en lo más mínimo la consistencia de nuestra argumentación, que los derechos morales deberían ser expandidos a otros seres distintos de los humanos. Así, por ejemplo, si evitar el dolor es una propiedad relevante para atribuir derechos, deberíamos, si queremos ser consecuentes, extender la comunidad moral a los animales indudablemente sensibles. Singer, el filósofo que ha desarrollado más extensamente las consecuencias de tomarse en serio el argumento de la igual consideración de intereses, sostiene que el especismo ${ }^{16}$ es una forma de discriminación en base a la especie equivalente al racismo o similar al sexismo. Éste se sustenta en una batería de argumentos teológicos vinculados con la carencia de alma inmortal, racionalidad y cultura que afectaría a los animales no humanos, lo que justificaría su inferioridad de estatus y explicaría su existencia por su servicio al grupo de estatus superior. ${ }^{17}$ El filósofo australiano se apura en aclarar, acto seguido, que el especismo es una forma de analfabetismo moral más que biológico. El problema no es, en verdad, que las diferencias se exageren para hacernos creer que los animales no sufren o sufren menos que los seres humanos, sino que se interpreta erróneamente la relevancia moral de las diferencias. El autor postula que entre todos los seres vivos sensibles debe haber una igualdad de consideración frente al sufrimiento en razón que el interés de evitar el sufrimiento es universal, por lo que mientras sea de la misma entidad e intensidad, con independencia de quien lo padezca, debe tener la misma relevancia moral.

Lo central es, entonces, relacionar correctamente las capacidades y el sufrimiento; así, por ejemplo, no puede justificarse la dolorosa amputación de la cola de algunos perros porque el gusto estético lo exige o tampoco puede defenderse el corte de los picos de los pollos en las granjas industriales por la incapacidad avícola para declamar. Todavía más, ni siquiera existe una relación necesaria entre una capacidad de entendimiento limitada y sufrimientos menos intensos. Así, por ejemplo, un bebé de pocos meses padece un dolor muy fuerte cuando su madre y padre lo dejan por unos minutos pues no comprende que éstos volverán muy pronto. La incapacidad del bebé para comprender lo que sucede no aminora sino que agudiza su experiencia dolorosa. Estas diferencias en las capacidades,

\section{${ }^{15}$ Ibid., p. 47}

${ }^{16}$ Del inglés specism, término acuñado por Richard D. Ryder. Traducido al castellano también como especieísmo (Mosterín, J. ;Vivan los animales!, Debate, Madrid, 1998). Para una presentación general excelente del tema de la extensión de la ética más allá de la humanidad, puede verse de Lora, Pablo, Justicia para los animales, Alianza, Madrid, 2003.

${ }^{17}$ Baste recordar aquí un pasaje del Génesis: "Díjose entonces Dios: Hagamos al hombre a nuestra imagen y semejanza, para que domine sobre los peces del mar, sobre las aves del cielo, sobre los ganados y sobre las bestias de la tierra, y sobre cuantos animales se mueven sobre ella. Y creó Dios al hombre a imagen suya, a imagen de Dios le creó, y los creó macho y hembra; y los bendijo Dios, diciéndoles: Procread y multiplicaos, y henchid la tierra; sometedla y dominad sobre los peces del mar, sobre las aves del cielo y sobre los ganados, y sobre todo cuanto vive y se mueve sobre la tierra”. 
en consecuencia, no justifican diferencias de consideración moral. En definitiva, desde un punto de vista que considera imparcialmente los intereses, éstos varían en razón de su contenido, no según el sujeto. Por último, Singer aclara que rechazar el especismo no significa pensar que es lo mismo matar a una persona que a cualquier animal. Quitar la vida a una criatura capaz de concebirse a sí misma como un ser que existe en el tiempo, que tiene recuerdos y anhelos, que aprende, que tiene la posibilidad de amar es mucho más grave que quitársela a un ser que no posee estas facultades. Como se ve, el autor sostiene una igualdad ante el sufrimiento y una desigualdad en relación a la muerte. Esto no es contradictorio, el interés en seguir viviendo es muy distinto al interés en evitar el dolor. ${ }^{18}$

\section{LA TEORÍA PUESTA A PRUEBA: ¿SON LOS NIÑOS TITULARES DE DERECHOS?}

En este apartado lo que intentaré hacer es mostrar como la posible solución al problema, que ya esbocé más arriba, sobre la titularidad de los derechos humanos, tratándose de sujetos que carecen total o parcialmente de personalidad moral, es una aplicación de la propuesta de Nino desplegada para resolver las paradojas apuntadas en el acápite anterior.

El filósofo Neil MacCormick ${ }^{19}$ sostuvo que la idea de los derechos de los niños es difícil de encuadrar dentro de las teorías tradicionales referidas a qué significa tener un derecho a algo. En este sentido, los derechos de los niños son, entonces, una compleja prueba para las teorías que explican, en general, la noción de "derecho". Veamos, pues, si las diferentes doctrinas existentes sobre la cuestión de la atribución de los derechos tienen una respuesta satisfactoria cuando hablamos de los derechos de la infancia. Y mi punto de partida será el siguiente: cualquier teoría de los derechos debe enunciarse de tal forma que incluya a los niños, niñas y adolescentes como titulares de derechos, de lo contrario es una teoría conceptualmente insatisfactoria y, además, moralmente indeseable.

18 Véase Singer, P., Liberación animal, Trotta, Madrid, 1990, especialmente pp. 37-59 (traducción de Paula Casal). Para una revisión crítica de las tesis de Singer, puede verse Carruthers, P. La cuestión de los animales, Cambridge University Press, 1995 (traducción de José María Perazzo).

19 Véase "Los derechos de los niños: una prueba para las teorías del derecho", en Derecho Legal y Socialdemocracia. Ensayos sobre Filosofía Jurídica y Política, Tecnos, Madrid, 1990, pp. 129-137 (traducción de M. Lola González Soler). Véase, además, en el ámbito hispanoamericano, los trabajos de Hierro, L. L., "Tienen los niños derechos”, en Revista de Educación, número 294, 1991, pp. 221-233 y “¿Derechos humanos o necesidades humanas? Problemas de un Concepto", en Sistema, Revista de Ciencias Sociales, Fundación Sistema, Madrid, número 46, 1982, pp. 45-61. También puede consultarse del mismo autor, "Los derechos de la infancia. Razones para una ley”, en Estudios jurídicos en homenaje al profesor Aurelio Menéndez, Volumen 4, Civitas, Madrid, 1996, pp. 5473-5493. 
En términos generales, existen dos tipos de teorías que responden de forma diversa a la pregunta por la titularidad de los derechos. ${ }^{20}$ Por un lado, están las teorías de la voluntad y, por otro, las teorías del interés. Las primeras ponen el acento en el poder o discreción del titular del derecho; las segundas, en cambio, priorizan el beneficio o el interés del titular. Dicho en otras palabras, las teorías de la voluntad -también denominadas teorías de la elección- sostienen que tener un derecho supone el reconocimiento moral o jurídico de la voluntad o discreción del titular que lo autoriza para entrometerse, en algún sentido, en la esfera de actuación de otros. Y las teorías del interés -conocidas también como teorías del beneficiario- postulan que tener un derecho es detentar un cierto beneficio o interés sin que necesariamente se pueda ejercer directamente, del cual se derivan deberes, morales o jurídicos, que se imponen sobre uno o más sujetos que deben respetar dichos intereses o beneficios.

Como se ve, las teorías de la voluntad se vinculan directamente con la fundamentación tradicional de los derechos civiles, particularmente aquellos de carácter patrimonial, cuyo origen se encuentra en las doctrinas liberales clásicas, herederas de las revoluciones del siglo XVIII, que justificaban la atribución de derechos subjetivos en la soberanía individual, manifestación de la libertad e igualdad originarias del ser humano considerado con un agente racional y plenamente autónomo. ${ }^{21}$

Claramente, en consecuencia, las teorías de la voluntad dejan fuera a los niños. ${ }^{22}$ Ahora bien, esto no significa, necesariamente, la incorrección de un principio moral que conlleve la protección de los niños y niñas, pero dicha preocupación no podría expresarse mediante la técnica habitual de los derechos. Esta afirmación que, a simple vista, parece inocua fue, por el contrario, una de las principales razones de la postergación durante mucho tiempo de los intereses de los niños, niñas y adolescentes. En efecto, gracias a

${ }^{20}$ Véase Hierro, L. L., “¿Derechos humanos o necesidades humanas? Problemas de un concepto”, ob. cit.

${ }^{21}$ Véanse Hierro, L. L., “'Tienen los niños derechos?”, ob. cit., y "Los derechos de la infancia. Razones para una ley”, ob. cit. Precisamente, en razón de esa libertad e igualdad de los seres humanos, que sólo se predica de una parte de éstos, que reúnen en el estado de naturaleza dichas características, fueron excluidos de la comunidad moral no sólo los niños, sino que también las mujeres y los no propietarios.

${ }^{22}$ Un buen ejemplo de una teoría de la voluntad de los derechos que excluye a los niños es el caso de la línea argumental trazada por Hart: "Es importante para toda la lógica de los derechos que, mientras se descubre a la persona que ha de beneficiarse con el cumplimiento de un deber considerando lo que sucederá si no se cumple el deber, a la persona que tiene un derecho (a quien se debe el cumplimiento) se la descubre examinando la transacción o situación antecedente o las relaciones de las partes donde surgió el 'deber'. Estas consideraciones debieran inclinarnos a no extender a los animales y los niños, a quienes debemos tratar bien, la noción de un derecho al buen trato, porque la situación moral puede describirse de manera sencilla y adecuada afirmando que es malo maltratar animales o niños, o que no debemos tratarlos mal, o bien, en el sentido generalizado que del 'deber' tiene el filósofo, que tenemos el deber de no tratarlos mal. Si el uso común sanciona el que hablemos de los derechos de los animales o los niños, hace un uso ocioso de la expresión 'un derecho', que confundirá la situación con otras situaciones morales diferentes donde la expresión 'un derecho' tiene una fuerza específica y no puede ser sustituida por las otras expresiones morales que he mencionado”. Hart, H.L.A., “Existen derechos naturales?”, en Filosofía Política, Fondo de Cultura Económica, México D. F., 1974, pp. 92 y 93 (traducción de E. L. Suárez). 
ellas se construyó la noción del derecho de menores tradicional, ${ }^{23}$ es decir, aquel que se edificaba sobre el supuesto de que los niños debían estar supeditados a la tutela heterónoma familiar o estatal y que, por lo mismo, debían ser considerados como meros recipientes de las políticas o cuidados diseñados por otros, sustentados en la buena voluntad y la generosidad propias de un buen padre de familia, que deciden por ellos sin considerar su opinión ni su autonomía progresiva. Por estas mismas razones, tampoco es satisfactoria la solución de la representación por parte de terceros de los intereses de los niños, niñas y adolescentes. Debemos, entonces, para tomarnos los derechos de éstos en serio, entenderlos de un modo distinto.

Esa otra manera es, precisamente, la que nos ofrecen las teorías del interés o del beneficiario. Para MacCormick, "la atribución de un derecho a determinada clase de seres parece exigir las siguientes presunciones: respecto a la clase en cuestión (en nuestro caso, niños), existe cierta acción u omisión (en nuestro caso, las acciones y omisiones que conllevan el cuidado, alimento y cariño) cuyo cumplimiento, en el caso de todos y cada uno de los miembros de esa clase, satisfará, protegerá o mejorará cierta necesidad, interés o deseo de cada una de tales personas; y, en segundo lugar, la satisfacción de esa necesidad, interés o deseo es de tal importancia que sería incorrecto negarla a cualquier persona independientemente de las ventajas ulteriores que ello supone". ${ }^{24}$ Por lo tanto, la noción de derecho debe ser reformulada, conforme a la teoría del interés de MacCormick, con el fin de incluir a los niños, niñas y adolescentes como titulares de los mismos. Así, esta nueva enunciación se expresa del siguiente modo: Todos los miembros de la clase $\mathrm{C}$ (niños, niñas y adolescentes) tienen derecho a recibir un determinado $\mathrm{T}$ (tratamiento), siempre que $\mathrm{T}$ sea un bien de tal importancia que sea incorrecto negarlo a cualquier miembro de la clase C. ${ }^{25}$

Como se ve, el autor en comento enuncia la noción de derechos humanos como necesidades y esto le permite incluir, sin forzar el lenguaje, a los niños, niñas y adolescentes como titulares directos de los derechos humanos. Pero ¿qué debemos entender por necesidad? En principio, se presenta como suficientemente claro que lo debido, en justicia, es satisfacer a todas las personas sus necesidades básicas, es decir, intentar fundamentar que existe un derecho humano a la satisfacción igual de las necesidades básicas. De este modo, la primera cuestión a resolver es qué debemos entender por necesidades

${ }^{23}$ Para un análisis general de las características del paradigma tutelar, propio del derecho de menores tradicional, puede verse García Méndez, E., Derecho de la infancia-adolescencia en América Latina: de la situación irregular a la protección integral, Forum Pacis, Santa Fe de Bogotá, 1994; Millán, P. y Villavicencio, L., "La representación de niños, niñas y adolescentes en los procedimientos para la adopción de medidas de protección”, en Revista de Derechos del Niño, número 1, Universidad Diego Portales, Santiago, 2002, pp. 44-48; y Peña, C., "El derecho civil en su relación con el derecho internacional de los derechos humanos", en Sistema jurídico y derechos humanos, Cuadernos de Análisis Jurídico, serie Publicaciones Especiales, número 6, Universidad Diego Portales, Santiago, 1996, pp. 626-630.

${ }^{24}$ MacCormick, N., ob. cit., p. 133.

${ }^{25}$ Ibid. 
básicas. ${ }^{26}$ Parece claro que la idea de necesidad se asocia a la autorrealización o autonomía personal, por lo tanto, se relaciona con el libre desarrollo de las capacidades individuales con el fin de construir una sociedad que haga posible el desarrollo individual autónomo de las personas, liberando a los sujetos de las cargas propias de las circunstancias de las cuales no son causantes y permitiendo que sean dueños y responsables de su destino. ${ }^{27}$ Las necesidades serían, entonces, prerrequisitos de la autonomía personal. Toda sociedad que se autodenomine justa debería satisfacer este tipo de necesidades, puesto que son la base de las actividades y proyectos personales.

Hasta ahora he dicho que las necesidades básicas se vinculan al desarrollo de las personas como agentes morales, pero todavía queda por analizar el problema de la métrica, es decir, de qué forma medimos las necesidades asociadas a los diferentes planes de vida que las personas escogen, libremente, para sí. Quizás la salida sea optar por un camino diverso. ${ }^{28}$ En efecto, creo que es equívoco partir desde un punto de vista que atribuye una intencionalidad a las necesidades básicas. Más fructífero es defender un concepto de necesidades básicas a partir de ciertos rasgos mínimos que permitan una especificación del mismo concepto. El comienzo, entonces, debe ser el carácter no intencional de éstas, es decir, no las elegimos, en consecuencia, no es un campo de acción respecto del cual podamos actuar positiva o negativamente. Por esta razón, sólo lleva a confusiones sostener que una necesidad básica existe a partir de los objetivos, propósitos o fines hacia los cuales se dirige la conducta de una persona. En vez de eso, no sólo podemos no tener razones para necesitar algo, sino que no tenemos por qué detentar alguna razón para experimentar una necesidad básica. Dicho de otra manera, no tenemos por qué justificar la existencia de nuestras necesidades básicas con razones.

De este modo, la "necesidad es una situación o estado siempre predicado de una persona y que tiene un carácter insoslayable para ella”. ${ }^{29}$ Más específicamente, las necesidades básicas son "aquellas situaciones o estados que constituyen una privación de aquello que es básico e imprescindible y que, en consecuencia, nos pone directamente en relación con la noción de daño, privación o sufrimiento grave para la persona”. ${ }^{30}$ Estas situaciones en las que se puede encontrar un sujeto y respecto de las cuales no puede escapar están íntimamente relacionadas o repercuten en forma directa en la calidad de vida humana y comparten la característica esencial que nos permite hablar, con propiedad, de necesidades básicas: el perjuicio o grave menoscabo va a mantenerse, salvo que esa

${ }^{26}$ Para una aproximación general a la noción de necesidades y su relación con la idea de derechos puede verse Añón, M. J., Derechos y necesidades. Un ensayo de fundamentación, Centro de Estudios Constitucionales, Madrid, 1994, especialmente pp. 259 y ss.

${ }^{27}$ Gargarella, R., Las teorías de la justicia después de Rawls, Paidós, Barcelona, 1999, pp. 107 y 108.

${ }^{28}$ Sigo a Añón en el desarrollo de esta idea. Véase Añón, M. J., ob. cit., pp. 265 y ss.

29 Ibid., p. 266.

${ }^{30}$ Loc. cit. 
situación se vea satisfecha, cumplida o realizada y no hay ninguna posibilidad disponible para escapar de ella. ${ }^{31}$

Según todo lo dicho, en conclusión, no requerimos - como pensaba Hart- forzar la teoría para postular que los niños, niñas y adolescentes tienen derechos, aunque no puedan hacerlos valer por sí mismos en todos los casos y muchos de ellos sean irrenunciables. Antes más bien, debemos sostener que todo niño, niña y adolescente tendrá un derecho si existe una necesidad cuya satisfacción se sustenta en razones suficientes para exigir en todo caso. Desde este enfoque, esquivamos el peligro de aseverar débilmente que es bueno tratar bien a los niños sino que, al contrario, probada la existencia de un derecho, sustentado a su vez en una necesidad, debe determinarse sobre quiénes recae el deber correlativo, estableciéndose los sujetos pasivos obligados. ${ }^{32}$

\section{IV. ¿QUÉ CLASE DE DERECHOS SON LOS DERECHOS HUMANOS?}

Un último punto conceptual, que suele generar confusiones, es la especie de derechos a la que se alude cuando se habla de derechos humanos. Es una cuestión central preguntarse si los derechos humanos son de índole jurídica o moral o si pueden ser a la vez jurídicos y morales. A primera vista, parece obvio que cuando se habla de derechos humanos se alude a situaciones normativas que están estipuladas en disposiciones de derecho positivo nacional e internacional, como son, por ejemplo, el artículo $19 \mathrm{~N}^{\circ} 7$ de la Constitución y el artículo 7 de la Convención Americana sobre Derechos Humanos. Según esta interpretación los derechos humanos serían primordialmente derechos jurídicos. Pero ¿qué sucede cuando los derechos humanos no están reconocidos en un ordenamiento? ¿Qué pasa cuando hay un régimen autoritario que dicta normas jurídicas que atentan contra las convicciones morales más íntimas?

Los derechos humanos surgieron como una técnica argumentativa eficaz para controlar y contrarrestar el poder estatal, luego no pueden tener solamente un reconocimiento positivo. ¿Cómo podrían ser eficaces en su objetivo primordial si dependen de los gobernantes de turno? En los contextos en que la alusión a los derechos humanos adquiere una importancia radical para cuestionar leyes, instituciones, medidas o acciones estos derechos no se identifican con los que surgen de normas del derecho positivo sino, en todo caso, se entiende que los derechos jurídicos así creados constituyen sólo una consagración o reconocimiento de aquellos derechos que son lógicamente independientes

${ }^{31}$ Una de las críticas más incisivas que puede hacerse a la teoría de los derechos como necesidades es su carácter fuertemente paternalista, ya que no habría manera, al parecer, de renunciar a los derechos. Esta objeción se salva, con cierta facilidad, si se vincula la idea de necesidad con la tesis de que la justificación de los derechos humanos es que deben distribuirse igualitariamente entre todos los seres humanos para que cada uno de ellos pueda desenvolverse adecuadamente como agente moral, por lo que una de las primeras necesidades que debe ser cubierta es, precisamente, aquella que tiene todo ser humano de vivir autónomamente.

${ }^{32}$ Hierro, L. L., “¿Tienen los niños derechos?”, ob. cit., pp. 227-228. 
de esa recepción jurídica. Se reclama el respeto de los derechos humanos aun frente a sistemas jurídicos que no los reconocen y precisamente porque no los reconocen. ${ }^{33}$

Sin duda, según lo visto, los derechos humanos forman parte del discurso moral, o sea, se vinculan a la tarea de determinar qué derechos deben ser otorgados a las personas. Pero la forma proposicional que éstos adoptan corresponde a un derecho subjetivo ${ }^{34}$ que supone el deber correlativo de otros. Desde este último punto de vista, uno podría

${ }^{33}$ Un sector relevante de la doctrina hispanoamericana considera equivocada la postura que sostiene que los derechos humanos son una clase de derechos morales. Véase, por ejemplo, en el ámbito español la tesis de Peces-Barba que niega la posibilidad de postular que los derechos humanos sean genuinos derechos subjetivos con prescindencia de su reconocimiento positivo y su eficacia real. Para el profesor español, la idea de derechos morales es una noción reduccionista que no permite una comprensión integral de los derechos humanos -que él prefiere llamar fundamentales- ya que constituyen una aproximación abstracta y ahistórica de los derechos que elude las conexiones necesarias con la evolución de la realidad social y prescinde de su faceta jurídica positiva. Peces-Barba, G., Curso de derechos fundamentales (I) Teoría General, Eudema, Madrid, 1991, ob. cit., pp. 19-51. Compartiendo la misma tesis, con matices más o menos, pueden verse, además, Muguerza, J., "La alternativa del disenso", en El fundamento de los derechos humanos, Gregorio Peces-Barba (ed.), Debate, Madrid, 1989, pp. 19-56, y Pérez Luño, A., "Concepto y concepción de los derechos humanos”, en Doxa, Cuadernos de Filosofía del Derecho, número 4, Universidad de Alicante, 1987, pp. 47-66. En mi opinión, Peces-Barba se equivoca y confunde dos planos distintos. Una cuestión son los derechos que todo ordenamiento debería reconocer y que constituyen una exigencia moral permanente para todo sistema jurídico y otra distinta son los derechos que de hecho son articulados por un sistema jurídico determinado. Si siguiéramos la tesis del autor no podríamos argumentar que una dictadura viola derechos humanos si las normas jurídicas positivas que ese régimen autoritario ha producido los desconocen. Con todo, la tesis que defiendo no necesita ser iusnaturalista.

Como un autor representativo que se sitúa en la trinchera opuesta a Peces-Barba, puede citarse el caso de Francisco Laporta. El profesor Laporta considera que la única condición que debe satisfacerse para ser titular de derechos humanos es la de ser humano, por ende, en la Alemania nazi o en la dictadura de Pinochet, por ejemplo, se violaron gravemente los derechos humanos, sea cual fuere el sistema jurídico-positivo imperante. La única vía de conferir un significado libre de aporías a los derechos humanos es considerarlos como derechos contrafácticos de índole moral, de forma tal que los órdenes jurídicos que no los reconozcan traicionan exigencias morales de gran importancia y violan derechos. Véase Laporta, F., "Respuesta a Pérez Luño, Atienza y Ruiz Manero", en Doxa, Cuadernos de Filosofía del Derecho, número 4, Universidad de Alicante, 1987, pp. 71-77. Y también en la misma publicación el artículo de Laporta "Sobre el concepto de derechos humanos", ob. cit., pp. 23-46.

En fin, Liborio Hierro parece situarse en una posición intermedia. En efecto, Hierro considera que los derechos humanos tienen un fundamento moral, sin embargo, la articulación específica de los derechos está sometida a vicisitudes históricas contingentes. Cada derecho humano-como facultad moral- tendría un núcleo no regateable, pero su reconocimiento se sometería a las circunstancias fácticas especiales de un determinado sistema jurídico, particularmente esto sucedería en el caso de un derecho humano tan básico como la igualdad, ya que ésta exige, conceptualmente, tratamientos comparativos que se harían necesariamente al interior de cada Estado. Véase Hierro, L. L., "El concepto de justicia y la teoría de los derechos", en Estado, justicia, derechos, Elías Díaz y José Luis Colomer (eds.), Alianza, Madrid, 2002, pp. 35-49.

${ }^{34}$ El concepto de derecho subjetivo es uno de aquellos conceptos jurídicos fundamentales que preocupa a la teoría general del derecho. Por supuesto, su caracterización rebasa, con creces, las posibilidades y objetivo del presente trabajo. Para una aproximación a la definición de derecho subjetivo, véase Hierro, L. L., "El concepto de justicia y la teoría de los derechos", ob. cit., pp. 35-41, y Hierro, L. L., "Conceptos jurídicos fundamentales (I). De las modalidades deónticas a los conceptos de derecho y deber", en Revista Jurídica de la Universidad Autónoma de Madrid, Dykinson, N³, Madrid, 2000, pp. 139-173; y Nino, C. S. Ética y derechos humanos, ob. cit., pp. 25-48. 
sostener que son parte del discurso jurídico; sin embargo, si el principal objetivo y lo que hace particularmente importante a los derechos humanos es que sirven para evaluar, criticar y deslegitimar las normas positivas. Si lo que distingue a los derechos humanos es, precisamente, que se contraponen a sistemas jurídicos que no los reconocen y especialmente porque no los admiten, es forzoso concluir que los derechos no habitan en el discurso positivo sino que en el discurso moral. Son una clase de derechos morales.

Es obvio que no todos los derechos morales constituyen aquello que se suele aludir con el rótulo "derechos humanos". Por ejemplo, todos tenemos el derecho moral a que nuestros amigos nos devuelvan los libros que les prestamos pero, si no lo hacen, difícilmente podremos recurrir a la Comisión Interamericana de Derechos Humanos para recuperarlos. Un claro rasgo distintivo de los derechos humanos es que éstos versan sobre bienes de importancia primordial para sus titulares. Sin embargo, esta propiedad no parece ser suficiente para distinguir los derechos humanos de otros derechos morales: el acceso a libros es primordial para un intelectual y el contar con fertilizantes puede ser vital para un agricultor, pero nadie vería la supresión de estos bienes como una violación de los derechos humanos. Es necesario, entonces, agregar algo más para distinguir los derechos humanos de los derechos morales además de su identificación con bienes de importancia primordial o básica para sus titulares. Este rasgo pareciera ser, siguiendo a Nino, que los derechos humanos tienen como titulares a todos los hombres y mujeres, por ende, su posesión no puede estar restringida a subclases de individuos humanos. ${ }^{35}$

El profesor Hierro tiene una opinión ligeramente distinta. Si bien comparte con Nino la idea de que no cabe comprender dentro del concepto de derechos humanos todos los deseos, intereses o necesidades de una persona y, además, no todas las posiciones que pueden articularse como derechos subjetivos son derechos humanos, difiere en cuanto al criterio. Para él, sólo merecen tal rótulo aquellas posiciones que satisfacen el requisito de ser condición necesaria e indispensable para que todo ser humano pueda desenvolverse igualitariamente como agente moral. Que sean una condición necesaria significa, por una parte, que la noción incluye todas y cada una de las posiciones normativas cuya negación o desconocimiento acarrearía una limitación inadmisible al titular del derecho para desenvolverse como agente moral. Y, por otra parte, implica que la definición excluye cualquier situación normativa cuyo reconocimiento no es necesario para que la persona se desarrolle como agente moral. ${ }^{36}$

${ }^{35}$ Nino, C. S., Ética y derechos humanos, ob. cit., pp. 40-41.

${ }^{36}$ Hierro coloca el siguiente ejemplo para puntualizar lo que debe incluirse y lo que debe excluirse: "La inclusión supone, por ejemplo, que en un contexto social con un alto grado de comunicación escrita la pretensión de recibir una alfabetización que permita operar en condiciones básicas de competencia comunicativa se convierte en un derecho humano; la exclusión supone, por ejemplo, que en un contexto social en que el conocimiento del idioma ruso no es un requerimiento básico para la competencia comunicativa la pretensión de recibir enseñanza del idioma ruso no es un derecho humano". Hierro, Liborio L., "El concepto de justicia y la teoría de los derechos", ob. cit., p. 40. Puede verse claramente que este criterio se relaciona con una cierta tesis liberal-igualitaria en materia de justicia distributiva. Lo que intentan hacer los igualitaristas en general es distinguir, para efectos de la redistribución de los recursos, entre hechos arbitrarios desde un punto vista moral (ya sea producto del azar genético o social), es decir, de los cuales la persona no es responsable y hechos de los cuales toda persona debe ser considerada responsable. Para que una sociedad 


\section{CONCLUSIÓN}

Para finalizar este trabajo, sólo quisiera apuntar algunas ideas, a modo de síntesis, vinculadas con los inconvenientes relacionados con la adopción de un concepto plenamente adecuado de derechos humanos. En el apartado inicial, lo que intenté hacer es presentar algunos problemas que se siguen de los criterios tradicionalmente defendidos para determinar la clase de los sujetos que son titulares de derechos humanos. Dichas dificultades son de dos tipos. En primer lugar, aquel grupo de paradojas que chocan con nuestras intuiciones morales más básicas como sucede cuando, de seguir el criterio de la personalidad moral, debemos llegar forzosamente a la conclusión de que hay seres humanos que no deberían ser titulares de esos derechos o, al menos, ofrecerían un título fuertemente debilitado, siendo la alternativa igualmente contraintuitiva: la idea que, sustentada en la potencialidad, pretende equiparar moralmente los óvulos fecundados con las personas nacidas. Y, en segundo lugar, tenemos un conjunto de complicaciones de índole metodológica, que agrupé en torno a la falacia naturalista, que arrincona a quienes pretenden hacer depender la titularidad de los derechos humanos del hecho de compartir una cierta propiedad biológica.

La forma de eludir esos dilemas es, como se ha defendido en este trabajo, ocuparnos de la cuestión de la titularidad sólo una vez que hemos dilucidado cuáles son los principios morales de los cuales se derivan los derechos humanos. Así pues, la clase de los sujetos que consideremos morales en algún sentido dependerá de si comparten o poseen aquellas propiedades normativas que hemos entendido previamente como relevantes. Por ejemplo, si la igual consideración de los intereses nos lleva -en el estadio de una deliberación práctica sujeta a ciertas constricciones ideales- a determinar que la evitación del dolor es valiosa, en un segundo momento habremos de concordar que ello nos compele a extender, para esa propiedad por lo menos, la comunidad moral a sujetos que no pertenecen a nuestra especie. Obviamente, esta exigencia nos genera una fricción con nuestros prejuicios irreflexivos, pero que deberíamos aceptar una vez que éstos han sido contrastados con los principios que consideramos moralmente significativos. Por supuesto que persiste un inconveniente terminológico: ¿cómo podemos hablar de derechos humanos cuando sus titulares son, tratándose de determinados derechos y en ciertos casos, individuos de otra especie? La respuesta es sencilla: usamos la expresión "derechos humanos", como cualquier otro concepto, por su capacidad de economizar las palabras a las que debemos echar mano para comunicarnos unos con otros. Si, a veces, ese concepto ha de ser precisado en el sentido de que, por ejemplo, el derecho a no ser torturado debería extenderse a otros seres distintos de los humanos, pues tendremos que hacerlo.

Por otra parte, una forma de poner a prueba la tesis que acabo de describir es analizar el modo en que podemos atribuir derechos humanos a los niños. Y la teoría del interés

sea justa debe tender a igualar a las personas, lo más posible, en sus circunstancias de modo tal que lo que acaezca durante sus vidas sea achacable a su propio cometido y no al puro azar. De modo que el criterio expuesto busca neutralizar mediante la distribución igualitaria de un conjunto de derechos humanos básicos los efectos del azar o la suerte bruta. 
o del beneficiario, que da una respuesta satisfactoria al problema de la titularidad de derechos en caso de personas menores de edad, es una aplicación consistente de aquella tesis, o sea, identificado un interés o beneficio que es moralmente relevante para ciertos sujetos, éste debe ser amparado por un derecho subjetivo con prescindencia de si sus titulares carecen parcial o totalmente de personalidad moral.

Por último, si los derechos humanos pretenden cumplir el valioso objetivo que se les atribuye, deben ser considerados como una clase de derechos morales pues su validez no puede depender de la circunstancia fáctica de ser aprobados por cada sistema jurídico. Ello nos lleva al problema de encontrar un fundamento suprapositivo para los derechos humanos -algo que no traté en estas líneas-, pero que demanda, al menos, una respuesta que escape de las objeciones a las que se exponen el iusnaturalismo y el positivismo. ${ }^{37}$

Podemos concluir, entonces, que deberíamos denominar como derecho humano a toda aquella posición o situación normativa que cumpla la siguiente formulación conceptual: Para todos y cada uno de los miembros individuales de la clase de los seres humanos, o de cualquier otra clase que satisfaga la propiedad normativa relevante, se les adscribe una determinada libertad (privilegio), pretensión (derecho), inmunidad, o potestad ${ }^{38}$ siempre que exista una razón moral fuerte que justifique el carácter necesario de ésta, ya sea para asegurar a cada sujeto perteneciente a la clase su realización igualitaria como agente moral o para salvaguardar la realización de una necesidad o interés relevante. ${ }^{39}$

${ }^{37}$ Esa vía intermedia probablemente sea el constructivismo ético, es decir, una tesis metaética que no es objetivista puesto que no defiende la idea de que el agente moral deduzca principios morales absolutos de una verdad objetiva universal, instalada en una constelación de valores absolutos que existen en alguna dimensión de la realidad. Pero que tampoco es subjetivista pues no suscribe la noción de que los juicios morales no pueden escapar de las preferencias puramente subjetivas y relativas del agente. En vez de todo ello, el constructivismo lo que hace es dotarnos de las herramientas necesarias para justificar un catálogo de principios morales básicos a los que arribaríamos si nos colocáramos en condiciones ideales de deliberación. Como sostiene Rawls, "el constructivismo kantiano sostiene que la objetividad moral ha de entenderse en términos de un punto de vista social adecuadamente construido y que todos puedan aceptar. Fuera del procedimiento de construir principios de justicia, no hay hechos morales". Rawls, J., "El constructivismo kantiano en la teoría moral”, ob. cit., p. 213. Véase, además, Álvarez, S., La racionalidad de la moral, Centro de Estudios Políticos y Constitucionales, Madrid, 2002, pp. 51-109, y Villavicencio, L., "La prioridad de la libertad de expresión", en Revista Jurídica de la Universidad Autónoma de Madrid, Dykinson, Madrid, $\mathrm{N}^{\circ}$ 9, 2003, pp. 165-206.

${ }^{38}$ Como se sabe, Hohfeld distingue cuatro distintos significados posibles de la palabra derecho entendida como correlato de obligaciones activas y pasivas. En primer lugar, un individuo puede tener la libertad (privilegio) de realizar algo, o sea, la posibilidad de disponer su actuar como guste, imponiéndose un deber de abstención (no-derecho) para otros; en segundo lugar, una persona puede tener la pretensión (derecho) de dirigir la conducta de otros y, por ende, se impone a los demás la obligación (deber) de hacer o no hacer alguna cosa; en tercer lugar, alguien puede gozar del derecho de que nadie se entrometa en su actuar, es decir, tener una determinada inmunidad, configurándose para los demás un deber de incompetencia, esto es, no entrometerse en esa esfera específica; y, por último, un sujeto puede poseer una potestad o facultad por sobre otros, estableciéndose para otros un deber de sujeción. Véase Hohfeld, W. N., Conceptos jurídicos fundamentales, Fontamara, México D.F., 1992 (traducción de Genaro Carrió).

${ }^{39}$ Cfr. Hierro, L., "El concepto de justicia y la teoría de los derechos”, ob. cit., pp. 35-41, Laporta, F., "Sobre el concepto de derechos humanos", ob. cit., pp. 23-46, y Nino, C. S., Ética y Derechos Humanos, ob. cit., pp. 31-40. 


\section{BiBLIOGRAFÍA CITADA}

Álvarez, S., La racionalidad de la moral, Centro de Estudios Políticos y Constitucionales, Madrid, 2002.

AÑón, M. J., Derechos y necesidades. Un ensayo de fundamentación, Centro de Estudios Constitucionales, Madrid, 1994.

Carruthers, P., La cuestión de los animales, Cambridge University Press, 1995 (traducción de José María Perazzo).

De Lora, P., Justicia para los animales, Alianza, Madrid, 2003.

García Méndez, E., Derecho de la infancia-adolescencia en América Latina: de la situación irregular a la protección integral, Forum Pacis, Santa Fe de Bogotá, 1994

Gargarella, R., Las teorías de la justicia después de Rawls, Paidós, Barcelona, 1999.

Hart, H.L.A., “¿Existen derechos naturales?”, en Filosofía Política, Fondo de Cultura Económica, México D. F., 1974 (traducción de E. L. Suárez).

Hierro, L., "Conceptos jurídicos fundamentales (I). De las modalidades deónticas a los conceptos de derecho y deber", en Revista Jurídica de la Universidad Autónoma de Madrid, Dykinson, $\mathrm{N}^{\circ}$ 3, Madrid, 2000, pp. 139-173.

- “DDerechos humanos o necesidades humanas? Problemas de un Concepto”, en Sistema, Revista de Ciencias Sociales, Fundación Sistema, Madrid, número 46, 1982, pp. 45-61.

- "El concepto de justicia y la teoría de los derechos", en Estado, justicia, derechos, Elías Díaz y José Luis Colomer (eds.), Alianza, Madrid, 2002, pp. 11-73.

- "Los derechos de la infancia. Razones para una ley", en Estudios jurídicos en homenaje al profesor Aurelio Menéndez, Volumen 4, Civitas, Madrid, 1996, pp. 5473-5493.

- "Tienen los niños derechos", en Revista de Educación, número 294, 1991, pp. 221-233.

Hohfeld, W. N. Conceptos jurídicos fundamentales, Fontamara, México D.F., 1992 (traducción de Genaro Carrió).

Hume, D., Antología, Edición de Vicente Sanfélix, Península, Barcelona, 1986.

Laporta, F., "Respuesta a Pérez Luño, Atienza y Ruiz Manero", en Doxa, Cuadernos de Filosofía del Derecho, número 4, Universidad de Alicante, 1987, pp. 71-77.

- "Sobre el concepto de derechos humanos", en Doxa, Cuadernos de Filosofía del Derecho, número 4, Universidad de Alicante, 1987, pp. 23-46.

MacCormick, N., "Los derechos de los niños: una prueba para las teorías del derecho", en Derecho Legal y Socialdemocracia. Ensayos sobre Filosofía Jurídica y Política, Tecnos, Madrid, 1990, pp. 129-137 (traducción de M. Lola González Soler).

Millán, P. y Villavicencio, L., "La representación de niños, niñas y adolescentes en los procedimientos para la adopción de medidas de protección”, en Revista de Derechos del Niño, número 1, Universidad Diego Portales, Santiago, 2002, pp. 44-48.

Mosterín, J., ; Vivan los animales!, Debate, Madrid, 1998.

Muguerza, J., "La alternativa del disenso", en El fundamento de los derechos humanos, Gregorio Peces-Barba (ed.), Debate, Madrid, 1989, pp. 19-56.

Nino, C., Ética y derechos humanos, Astrea, Buenos Aires, 1989.

- "Los titulares de los derechos humanos: el concepto de persona moral", en Filosofía del lenguaje, de la ciencia, de los derechos humanos y problemas de su enseñanza, Sociedad Filosófica Iberoamericana, Universidad Nacional Autónoma de México,1987, pp. 127-146.

Peces-Barba, G., Curso de derechos fundamentales (I) Teoría General, Eudema, Madrid, 1991.

PEÑA, C., "El derecho civil en su relación con el derecho internacional de los derechos humanos", en Sistema jurídico y derechos humanos, Cuadernos de Análisis Jurídico, serie Publicaciones Especiales, número 6, Universidad Diego Portales, Santiago, 1996, pp. 626-630. 
- "Sobre el concepto y el fundamento de los derechos humanos", en Cuadernos de Análisis Jurídico, Escuela de Derecho de la Universidad Diego Portales, $\mathrm{N}^{\circ} 27,1993$, pp. 7-20.

Pérez Luño, A., "Concepto y concepción de los derechos humanos", en Doxa, Cuadernos de Filosofía del Derecho, número 4, Universidad de Alicante, 1987, pp. 47-66.

RAWLS, J., "El constructivismo kantiano en la teoría moral", en Justicia como equidad. Materiales para una teoría de la justicia, Tecnos, Madrid, 1999, pp. 209-262 (traducción de Miguel Ángel Rodilla).

- Lecciones sobre la historia de la filosofía moral, Barbara Herman (comp.), Paidós, Barcelona, 2001 (traducción de Andrés de Francisco).

Ruiz Miguel, A., Una filosofía del derecho en modelos históricos, Trotta, Madrid, 2002.

Singer, P., Ética práctica, Cambridge University Press, 1995 (traducción de Rafael Herrera Bonet).

- Liberación animal, Trotta, Madrid, 1990 (traducción de Paula Casal).

VAldés, M., "El problema del aborto: tres enfoques", en Bioética y derecho. Fundamentos y problemas actuales, Rodolfo Vázquez (comp.), ITAM-Fondo de Cultura Económica, México D. F., 1999, pp. 129-150.

Villavicencio, L., "La prioridad de la libertad de expresión", en Revista Jurídica de la Universidad Autónoma de Madrid, Dykinson, No 9, Madrid, 2003, pp. 165-206. 